\title{
Prevalence of Aerobic Bacteria in the Hands of School-Going Children of Rural Areas of Eastern Part of Nepal
}

\author{
Gyanendra Ghimire ${ }^{1}$, Sanjeev Das Rajbhandari ${ }^{1}$, Dipendra Raj Pandeya, ${ }^{1}$ Yankpam Ibotomba \\ Singh $^{1}$, Binita Adhikari', Manoj Pradhan ${ }^{1}$
}

${ }^{1}$ Nepalese Army Institute of Health Sciences, Kathmandu, Nepal

\section{ABSTRACT}

Introduction: The aim of this study was to find out the prevalence of bacteria in hands of school going children in a rural area of eastern part of Nepal. Contaminated hands play a major role in faeco-oral transmission of diseases. The students can expose themselves to infection if they do not properly wash their hands before taking food. Methods: The study was done in a remote school of eastern part of Nepal in 2013. A prospective study was done on 200 school children of age group 10 years to 15 years. Swab samples collected from all the children were transported to the laboratory within one to two hours of its collection. The samples were kept in nutrient broth for overnight incubation. They were then sub-cultured aerobically at $37^{\circ} \mathrm{C}$ on $5 \%$ defibrinated sheep blood agar and MacConkey agar plates for 24-48 hrs. Then the plates were examined to quantify the organisms present according to Clinical Laboratory Standard Institute (CLSI) guidelines. Results: Out of 200 dominant hand swabs of school children of age group 10 years to 15 years, 52 children $(26.0 \%)$ were harboring pathogenic bacteria in their hands. The major aerobic pathogenic bacteria in hands were i.e. Staphylococcus aureus, Streptococcus spp, Enterococci spp, Escherichia coli, Klebsiellaspp, Acinetobactersppand Pseudomonas aeruginosa. In most of the hands normal flora like Diphtheroids spp, Coagulase negative Staphylococci (CONS), Micrococci spp and some yeast were found. Conclusion: The finding of the study concludes that there is high incidence of aerobic bacterial flora in the hands of school going children of eastern part of Nepal. The incidence of infection was due to lack of proper hand washing before meal. The school should be told to keep soaps in the toilets for hand washing and conduct continue health education about proper hand washing and maintain cleanliness both in the schools and at the community level.

Keywords: aerobic bacterial flora; hand washing, schoolchildren, Staphylococcus aureus

\section{INTRODUCTION}

Contaminated hands play a major role in faecal-oral transmission of diseases. The students can expose to infection if they do not properly wash their hands before taking food. ${ }^{1}$ Dr. Semmelweis Ignac in 1840 s was the first person who gave the clear evidence of hand hygiene when working in the great hospital of Vienna. He pointed to the link between

Correspondence: Gyanendra Ghimire, Department of Microbiology, Nepalese Army Institute of Health Sciences, Kathmandu, Nepal. Email:serratia7@gmail.com 
infection and unclean hands. Hand washing with soap and water is a universally accepted practice for reducing the transmission of potentially pathogenic microorganisms. ${ }^{2}$ Washing hands is believed to reduce infection transmission by washing off potential microorganisms and also by removing the dirt which could also harbor the microorganisms and allow their survival for longer period of time. ${ }^{3}$ Systemic reviews have pointed the effectiveness of hand washing in reduction of diarrhea and acute respiratory illness, the two major childhood killer diseases.As the practice of hand washing is poor, isolation of pathogenic microorganisms has been reported in a number of studies done among children. The occurrence of microbial flora, i.e. Staphylococcus aureus, Escherichia coli, Klebsiellaspp, Pseudomonas aeruginosa, Enterococci spp and some yeast on hands in school children are common findings. ${ }^{4}$ The common pathogens that may be present on the skin as transient flora and can cause infectious diarrhea include: Escherichia coli, Staphylococcus aureus, Salmonella spp, Shigellaspp, Clostridium perfringens, Giardia lamblia, Norwalk virus and Hepatitis A and E viruses. ${ }^{5,6,7}$

The main objectives of the study was to find out the prevalence of bacterial contamination of hands of school going children and make them to understand the importance of hand washing before meal.

\section{METHODS}

A observational study was done in the Department of Microbiology laboratory, Nepalese Army Institute of Health Sciences, Kathmandu which included a total of 200 samples of school children between the age group 9-15 years in a school of eastern part of Nepal. Swabs were moistened with sterile saline and were swabbed over the hands and space between the fingers. The swab samples were collected just before the lunch break. Swab samples collected from all the children were transported to the laboratory within 2-4 hrs of its collection. At the laboratory, the swab samples were kept in nutrient broth for overnight incubation. They were then subcultured aerobically at $37^{\circ} \mathrm{C}$ on $5 \%$ defibrinated sheep blood agar and MacConkey agar plates for $24-48 \mathrm{hrs}$. and the plates were examined to quantify the organisms present.A questionare was asked to all the students about use of any antiseptic lotions or soap before lunch break. Before each school was visited, care was taken to notify the Head Masters/ Mistress and other staff about the investigation to be carried. The total population available for screening was identified from the class register. The colony count was evaluated and organisms were identified according to the Clinical Laboratory Standard Institute (CLSI) guidelines. Subsequently details of the child i.e. age, sex and grade were mentioned on the outer surface of the test tubes. ${ }^{8,9}$

Table 1: Sex wise distribution of pathogenic strain and non-pathogenic strains in dominant hands of children. $P$ value was 0.005 .

\begin{tabular}{|lccc|}
\hline Gender & Total (n) & $\begin{array}{c}\text { Pathogenic } \\
\text { bacteria (n) }\end{array}$ & $\begin{array}{c}\text { Non- } \\
\text { pathogenic } \\
\text { bacteria }\end{array}$ \\
\hline Male & 129 & 36 & 93 \\
Female & 71 & 16 & 55 \\
Total & $\begin{array}{c}\mathbf{2 0 0} \\
(\mathbf{1 0 0 \% )}\end{array}$ & $\mathbf{5 2}(\mathbf{2 6 \%})$ & $\begin{array}{c}148 \\
\mathbf{( 7 4 . \% )}\end{array}$
\end{tabular}


Table 2:Prevalence based on age

\begin{tabular}{|l|cc}
\hline Age & $\begin{array}{c}\text { Total } \\
\text { number of } \\
\text { children }\end{array}$ & $\begin{array}{c}\text { Number of children } \\
\text { having pathogenic } \\
\text { isolates }\end{array}$ \\
\hline $7-9$ yrs & 85 & $16(30.77 \%)$ \\
\hline $10-12$ yrs & 80 & $25(48.07 \%)$ \\
\hline $13-15$ yrs & 35 & $11(21.15 \%)$ \\
\hline Total & 200 & $52(26.00 \%)$
\end{tabular}

Table 3: Pattern of bacterial infections among students

\begin{tabular}{lcr}
\hline Bacteria & $\begin{array}{c}\text { Positive } \\
\text { (n) }\end{array}$ & \multicolumn{1}{l}{ Percentage } \\
\hline Gram positive cocci & & \\
$\begin{array}{l}\text { Staphylococcus } \\
\text { epidermidis }\end{array}$ & 104 & $52.0 \%$ \\
$\begin{array}{l}\text { Micrococci sps } \\
\text { Staphylococcus }\end{array}$ & 19 & $9.5 \%$ \\
$\begin{array}{l}\text { saprophyticus } \\
\text { Staphylococcus aureus }\end{array}$ & 11 & $27.5 \%$ \\
\hline Streptococcus sps & 7 & $5.5 \%$ \\
\hline Enterococci sps & 4 & $3.5 \%$ \\
\hline $\begin{array}{l}\text { Gram positive bacilli } \\
\text { Diphtheria sp }\end{array}$ & 137 & $2.0 \%$ \\
\hline Gram negative bacilli & & $68.5 \%$ \\
\hline Escherichia coli & 13 & $6.5 \%$ \\
\hline Klebsiellasps & 4 & $2.0 \%$ \\
\hline Acinetobactersps & 5 & $2.5 \%$ \\
\hline $\begin{array}{l}\text { Pseudomonas aeruginosa } \\
\text { Yeast like sps }\end{array}$ & 8 & $4.0 \%$ \\
\hline
\end{tabular}

\section{RESULTS}

A total of 200 children were included in the study. Both questionares were filled in and swab samples were taken from the dominant hands of school children of age group $10 \mathrm{yrs}$ to15 yrs. Out of which, 129 were male and 71 were female. 52 children $(26.0 \%)$ were found positive for various pathogenic bacteria in their hands. Male children showed relatively higher 36 (28.0\%) prevalence of infection than female children 16 (23.0\%) (Table-1). Maximum isolates of bacteria were found in hands of children in the age group of 9-12 years in both sexes (Table-2). Amongst gram positive isolates, Staphylococci, the commonest and among gram negative isolates, Escherichia coli was the common one. The other pathogenic isolates obtained are Streptococci spp, Enterococci spp, Klebsiellaspp, Pseudomonas aeruginosa and Acinetobacter spp. In most of the hands normal flora like Diphtheroids spp, Coagulase negative Staphylococci (CONS), Micrococci spp and some yeasts were found (Table -3).

In regards to students perception about the dirty areas of the hands, it was observed that majority $(70.0 \%)$ felt palm was likely to be more dirty while less than $60.0 \%$ felt that web spaces could harbor dirt. Others said that finger tips and nails are also equally common for the contamination. (Table-4).

Almost $80.0 \%$ of children reported that they always washed their hands before eating lunch. It was interesting to note that $70.0 \%$ students never used any soap to wash their hands before lunch. Most of them reported that there is washing facility near to the toilet of their schools but no soap and even no proper toilet. Regular hand washing before taking dinner was reported by $85.0 \%$ children. Almost all students reported that they always wash hands after defecation, while only $75.0 \%$ of them used soap. 
Table 4: Students' perception of the dirty areas of the hands

\begin{tabular}{lcc}
$\begin{array}{c}\text { Contaminated } \\
\text { areas of the } \\
\text { hands }\end{array}$ & $\begin{array}{c}\text { Number of } \\
\text { students }\end{array}$ & Percentage \\
\hline Palm & 140 & $70.0 \%$ \\
Web spaces & 120 & $60.0 \%$ \\
\hline Fingers & 110 & $55.0 \%$ \\
\hline Finger tips & 102 & $51.0 \%$ \\
\hline Nails & 90 & $45.0 \%$ \\
\hline
\end{tabular}

\section{DISCUSSION}

Nearly one fourth $52(26.0 \%)$ samples were positive for one or more pathogenic flora and in gender wise basis, male children showed relatively higher $36(28.0 \%)$ prevalence of infection than female children 16 (23.0\%) (Table-1). Based on the age of students, the highest prevalence of hand contamination was found among children aged 10-12 years 25 (48.07\%) (Table-2).

In the current study, practice of hand washing was found to be high; however, use of soap for hand washing was suboptimal, as has been seen in other studies from other countries. ${ }^{10}$ The present study findings are similar to a study on knowledge, attitude and practices of school children conducted in Ethiopia, which found that though most students reported hand washing before meals, i.e. $99.0 \%$, only $36.2 \%$ reported using soap during hand washing. ${ }^{11}$ The highest rate of prevalence among children might be due to lack of proper care of children by their parents, unhygienic behavior, lack of public health awareness and lack of sanitation and many of them are potent causes of infectious diarrhea. ${ }^{5,6,7}$ Diarrheal disease is the leading cause of childhood death and the second most common cause of death worldwide. Gastrointestinal infections have their major impact in the developing world. ${ }^{12}$ In our study it was found that Staphylococcus epidermidis is much more than that of Staphylococcus aureus on healthy skin (Table -3). They were gram positive cocci found in clusters. Most of them were coagulase negative (i.e. Coagulase negative Staphylococci). They were sensitive to $5 \mathrm{mcg} /$ disc strength of novobiocin which differentiated them from Staphylococcus saprophyticus which is novobiocin negative. Staphylococcus epidermidis is invariably present on normal human skin and is nonpathogenic ordinarily. ${ }^{12,13}$ Previously it was regarded as commensal microorganism on skin but nowadays it is seen as opportunistic pathogen. ${ }^{13,14}$ It can cause diseases when host's immune status has been imbalanced. ${ }^{14} \mathrm{~A}$ few of them may be blood culture contaminants. $^{5}$

Eleven isolates of Staphylococcus aureus were identified by colony morphology, gram stain, catalase and coagulase test.

Out of these 3 were lincomycin resistant and were thus methicillin resistant Staphylococcusaureus. The emergence of methicillin resistance is due to the acquisition mecA gene, encoding penicillin binding protein (PBP)2a. Normally b-lactum antibiotics bind to the PBPs in the cell wall, disrupt peptidoglycan layer synthesis and kill the bacteria. However, b-lactum antibiotics cannot bind to PBP2a, allowing a bacterium containing the mecA gene to survive b-lactam killing. ${ }^{15}$

In this study, all 5Staphylococcusaureus isolates were sensitive to vancomycin (Table 
-4), a common bacteria found on the skin and the nostrils of healthy people and animals.It is important because it has the ability to make different toxins that are frequently responsible for food poisoning ${ }^{15}$. Staphylococcus aureus is the only true pathogen included in the resident flora of skin. They colonize the skin, skin glands and mucous membranes. The most common source of infection is human patients and carriers, food and inanimate objects. The mode of transmission is by contact, direct fomites and airborne droplets. ${ }^{13}$ Seven isolates of Streptococcus species were identified and were chains of gram positive cocci and were catalase negative. Streptococcus species showed $\beta$-haemolysis on blood agar (Streptococcus pyogenes). Streptococcus sps forms part of normal flora of skin and known to cause both superficial and deep skin infections. ${ }^{16}$

Similarly 4 children were found to be having Enterococci sps positive. Enterococci sps are the normal flora of intestine and is one of the most important causative agent of acute diarrheal disease in children and adults. ${ }^{5,16} 30$ out of 52 children positive for pathogenic strains were found to be having gram negative bacteria in their hands and the bacteria isolated were Escherichia coli, Klebsiellasps, Pseudomonas sps and Acinetobactersps.

Different strains of Escherichia coli which are responsible to cause diarrhea and enterotoxigenic Escherichia coli among the most common cause of diarrhea among infants and children worldwide ${ }^{17}$. In our study 13 children were found to be having Escherichia coli in their dominant hands based on biochemical tests. In this study 4 children were found to be having Klebsiellasps positive. It is second most common species of human intestine and may cause septicaemia, pyogenic infections, diarrhea and pneumonia etc. ${ }^{5}$ The species was identified and confirmed by growing in Deoxycholate agar (blackish centre due to hydrogen sulphide gas production) and specific biochemical tests. ${ }^{7,15}$

Eight Pseudomonas sp and 4 Acinetobacter sp were isolated and identified by observing colony morphology, pigmentation, gram stain, non-lactose fermenters' oxidase test positive. All the species were imipenam sensitive. ${ }^{7}$

Micrococci, Diphtheroids and some yeast like species were isolated and identified by their morphology and gram staining. Most of the Diphtheroids are normal flora of skin, throat and conjunctiva. ${ }^{18,19}$ There may be anaerobic bacteria like Clostridia sp but were not isolated, may be due to the special conditions required for anaerobic cultivation.

The study shows that the children have high incidence of bacterial flora and majority of them have Staphylococcus spp. Staphylococcus epidermidis was the most common clinical isolate of the cutaneous microbiota and the finding is similar with shipra $\mathrm{S}$ et al and Congenet al. ${ }^{15,16}$ The study was done post-mansoon. It requires further study during pre-pre-mansoon and monsoon period to study the exact scenario.

\section{CONCLUSION}

The findings of the study concludes that hands of most students were found to be contaminated before taking food. Although they washed hands before meals, they hardly used soap due to lack of availability of soap at schools. Children should be often targeted for 
hygiene behavior as it is felt that habits that develop at their impressionable age would continue into their adulthood. However, due to lack of infrastructure which includes water and soap for hand washing, inculcating this habit would not be possible.

The study suggests that health education regarding proper hand washing and cleanliness should be implemented both in the schools and at the community. Improvement in habitation of hand washing, sanitation, access to health services, and appropriate available health infrastructure are important factors for decreasing the prevalence of infections in hands. The schools should ensure continue supply of water and soap in toilets for hand washing.

\section{REFERENCES}

1. Singh G, Urhekar R. Effects of hand wash agents: prevent the laboratory associated infections.IJMRHS. 2013; 2(3): 564-8.

2. Stone SP. Hand Hygiene- the case for evidence- based education. Journal of the Royal Society of Medicine. 2001;94(46): 278-81.

3. Roy SK, Amarchand R, Shrikanth J, Majumdar KK. A Study on Prevalence of Bacteria in the Hands of Children and Their Perception on Hand Washing in Two Schools of Banglore and Kolkata. Indian Journal of Public Health 2011; 55(4): 293-7.

4. Carrie A Japka, Campbell J Esther, Maxwell Sheri L. Hand Contamination and Transfer after Use of Contaminated BulkSoap Refillable Dispensers. Applied and Environmental Mycrobiology. 2011;77(9): 2898-2904.
5. Hedin G, Blomkvist A, Janson $M$ et al. Occurance of Potentially pathogenic bacteria on the hands of hospital patients before and after the introduction of patient hand disinfection. Actapathologica, M i c r o b i o log i c a, E t immunologicaScandinavica. 2012;120(10): 802-7.

6. Weinstein MP. Blood Culture Contamination: Persisting Problems and Partial Progress. Journalof Clinical Microbiology. 2003;41(6): 2275-8.

7. Taha RR, Alghalibi SM, SaeedSaleh MG. Salmonella spp. in patient suffering from Enteric fever and food poisoning in Thamar city, Yemen. Estern Mediterranean Health Journal. 2013;19(1): 88-93.

8. Kazuyoshi S, Yoshichika A, Kazumitsu N et al. Multi-focal outbreaks of Metallo-blactamase-producing Pseudomonas aeruginosa Resistant to broad Spectrum-bLactams, including Carbapenems. Antimicrobial agents and Chemotherapy. 1996;40(2):349-53

9. Collee JG, Marr W. Specimen collection, Culture containers and media. In: Collee JG, Fraser AG, Marmion BP and Simmons A.( $14^{\text {th }}$ ed. $)$. Mackie and McCartney Practical Medical Microbiology. New Delhi: Reed Elsevier India Private Limited; 2006: 95-7.

10. Curtis V, Danguah LO, Aunger RV. Planned, motivated and habitual hygiene behavior: An eleven country review. Health Educ Res 2009; 24: 655-73.

11. Vivas AP, Gelaye B, Aboset N, Kumie A, Berhane Y, Williams MA. Knowledge, attitudes and practices (KAP) of hygiene 